\title{
Radiological emergencies in a tropical climate country: Developing a multi-criteria decision tool
}

\author{
E.R.R. Rochedo ${ }^{1}$, M.A.V. Wasserman², D.N.G. Silva1, \\ P.R.R. Rochedo ${ }^{3}$ \\ ${ }^{1}$ Coordenação de Instalações Nucleares/CNEN, R. Passagem 123, $9^{\circ}$ andar, 22290-030 \\ Rio de Janeiro, RJ, Brasil \\ ${ }^{2}$ Instituto de Radioproteção e Dosimetria/CNEN, Av. Salvador Allende s/ No., 22780-160 \\ Rio de Janeiro, RJ, Brasil \\ e-mail: mwassermas@ien.gov.br \\ ${ }^{3}$ COPPEIPPE, Universidade Federal do Rio de Janeiro, Rio de Janeiro, RJ
}

\begin{abstract}
One of the permanent concerns in the international scenario is the study of the consequences of nuclear and radiological accidents and other events that lead to the contamination of the environment and the exposure of members of the public as a consequence of this contamination. Decision-making in such situations need to be based in solid technical criteria but must also take into account the actual prevailing circumstance in order to reach optimized measures to protect people and the environment. The Multi-criteria Analysis Method is already being used for similar applications in some European countries but it is necessary that the criteria are established taking in account economic, social and climatic aspects that can affect the selection of protective measures applicable to specific regions, and the selection of the different weights to be associated to the different criteria that are to be applied to different social-politic environments. The present work describes the developments to support the decision making process for the implementation of protective measures to protect the public in situations of radiological accidents in Brazil, the steps already developed and the current status of the system under development, discusses the difficulties found and stresses the needs for future developments.
\end{abstract}

\section{INTRODUCTION}

Decision making after an accident is a complex process as it includes a lot of uncertainty and are usually subjected to strong pressure mainly due to public anxiety. Since the accident in Goiânia, in 1987 [1], the Instituto de Radioproteção e Dosimetria (IRD) of the Brazilian National Nuclear energy commission (CNEN) started to develop tools to support the decision making processes after accidents involving nuclear or radiological exposure of the public. The experience with Goiania and other accidents with environmental contamination and the consequent exposure of members of the public has shown that criteria and methodologies needed to be set in advance as it was very difficult to introduce new concepts and methodologies after the accident [1-3].

Accidents that lead to environmental contamination may strongly affect local and regional population. Risks, size and type of contaminated areas, the number of persons potentially affected and public opinion are difficult to be held in a consistent way under the strong social pressure after such accidents. Decision making processes becomes very fragile, frequently leading to the implementation of non-justified measures, regarding both costs and exposure of emergency workers, if solid guidance and criteria are not developed prior to the accident. Besides that, optimization procedures are very difficult to be performed after an accident as the required information may not be promptly available.

The multi-criteria analysis (MCA) approach has been cited as being a useful tool to be used to support the decision making process after accidents [4]. With this tool, criteria may be established in advance leading to a selection of options that are technically justifiable, turning the decision process 
more reliable and transparent. This may be a relevant aspect to improve public acceptance about decisions and protective measures adopted.

The ultimate goal is to develop a multi-criteria tool to support the decision-making process after an accident. Decision-making in such situations need to be based in solid technical criteria but must also take into account the actual prevailing circumstance in order to reach optimized measures to protect people and the environment. The Multi-criteria Analysis Method is already being used for similar applications in some European countries [4,5]. But it is necessary that the criteria are established taking in account economic, social and climatic aspects that can affect the selection of protective measures applicable to specific regions, and the selection of the different weights to be associated to the different criteria that are to be applied to different social-politic environments.

\section{METHODOLOGY}

\subsection{Early developments}

The first step was the development of modeling tools to forecast doses to different groups of the public after an event of environmental contamination $[6,7]$. Uncertainty analysis pointed out the need for support by radioecological studies, as most data available in open literature has been derived in temperate climate countries and they could not be adequate for tropical climate areas [8].

The tropical radioecology project has been set up and incorporated the environmental modeling project. The main target area was the $50 \mathrm{~km}$ radius area surrounding the Brazilian Nuclear Power Plants, in Angra dos Reis. As data is being raised, they are immediately incorporate into the models. Currently the following resources have been develop and are available in Brazil:

- Urban area model adapted with shielding factors adequate to Brazilian building materials and typical Brazilian urban areas layout [9]; and

- Rural area model adapted with transfer factors determined for several radionuclides in most relevant Brazilian soil types [10].

\subsection{Current developments}

The next step was the study of protective and remediation measures to be applied in the protection of the public from exposure to ionizing radiation. The work includes several stages.

The first stage was the development of a database of countermeasures, including the main characteristics to be used as part of the criterion for a decision, such as effectiveness in reducing environmental concentration related to timing and seasonal aspects, wastes generation characteristics, feasibility and costs of implementation of the measures [11].

The efficiency of most countermeasures are described in literature according to their effect on reducing concentration of the surface or environmental media to which it has been applied. In order to assess its efficiency in reducing dose to the public, some standard scenarios were developed and simulations have been performed. For the urban areas, the basic urban environments already defined in previous works have been used, considering full occupation ( 24 hours per day) of each house or building [12]. For rural areas, relevant crops with their respective growing periods and transfer factors for the usual soil in the target area, as defined in previous works, has been used [10]. Additionally, a basic population diet was assumed based on the national food intake survey for the main towns closest to the target area [13].

\section{RESULTS AND DISCUSSION}

\subsection{Database}

The database includes 78 measures to be applied to urban, rural and aquatic environments. Countermeasures described in literature for forest areas could not be adapted for tropical rain forest due to the huge differences in the ecosystems involved and the usual uses by population. 
seasonal effect at short-term (1 month)

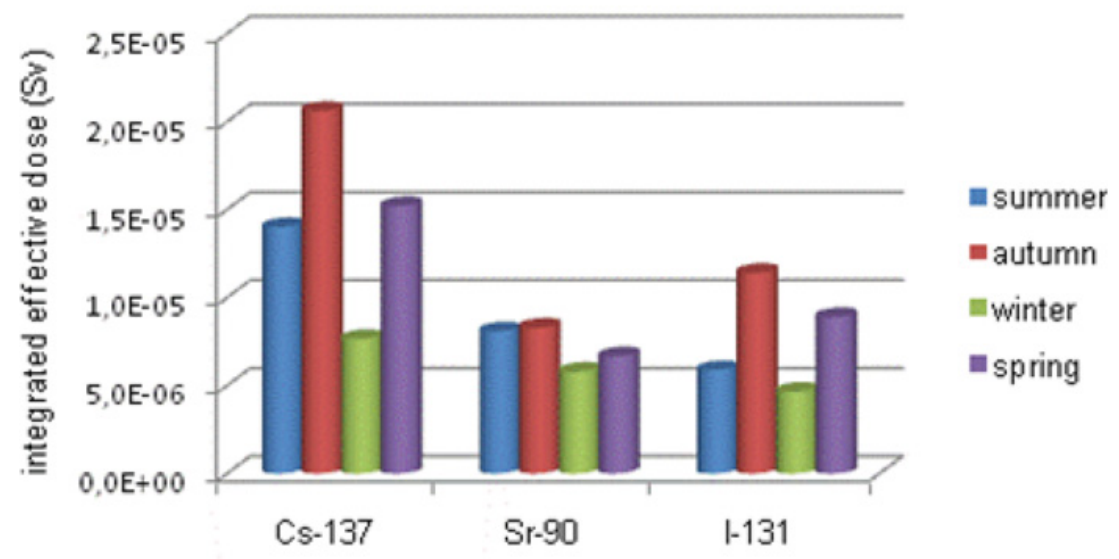

\section{seasonal effect at long-term ( 50 years)}

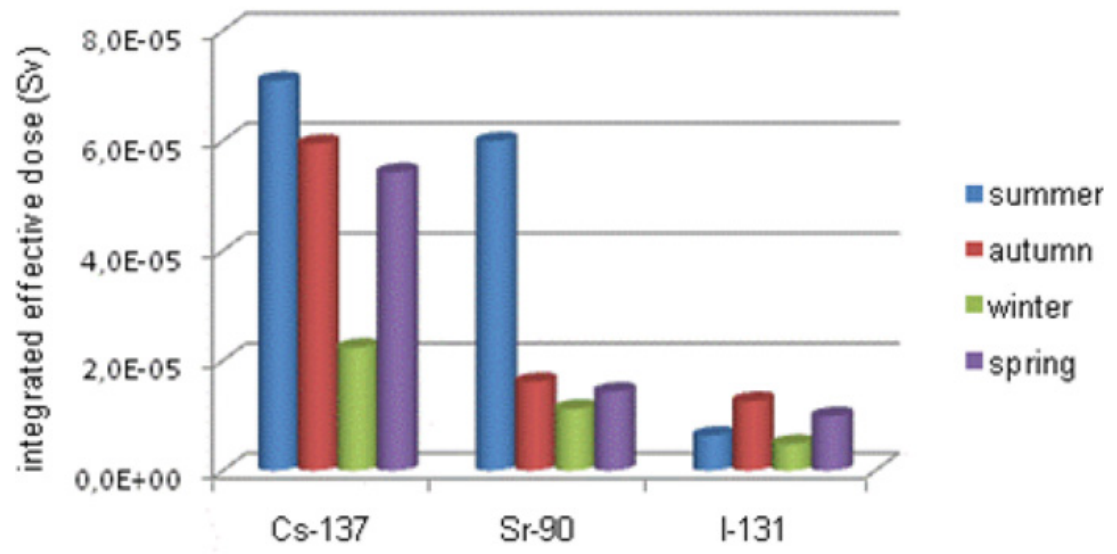

Figure 1. Example of seasonal effect on doses for the standard diet after a $1 \mathrm{kBq} / \mathrm{m}^{2}$ deposition.

The countermeasures have been classified according to their main characteristics. For urban areas, the countermeasures were classified as cleaning and decontamination procedures, covering the contamination, removing the contaminated surface and restriction on uses of areas.

For agricultural areas, the classification was related to change of agricultural practices, changes of uses of the contaminated area, dilution of contamination, removal of contamination and processing of products. Each countermeasure has been described by the following fields:

(a) Generic aspects: description of the countermeasure, type of surface to be treated, radionuclides to which the measure has been developed, summary description of the procedure, and information on the scale of application.

(b) Radiological aspects: exposure pathways, the efficiency on removing contamination with regards to the period of time elapsed since contamination, doses to workers and technical restrictions to its application.

(c) Infrastructure aspects: equipments, materials, specialized workforce and safety requirements; 

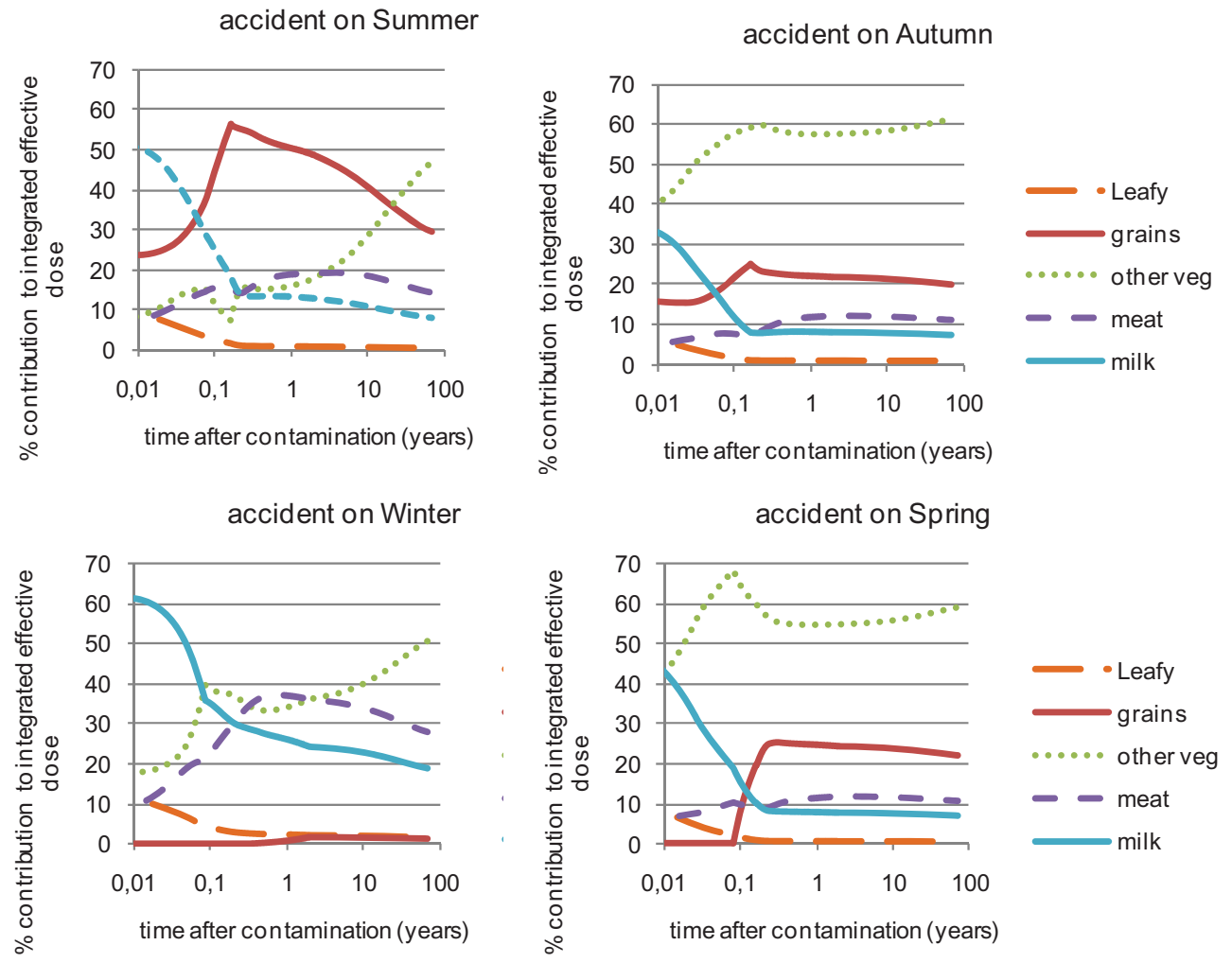

Figure 2. Percent contribution to integrated effective dose from different food items for Cs-137.

(d) Waste: qualitative and quantitative estimates of wastes generated by the application of the countermeasure; and,

(e) Sources of information, including the worldwide actual experience with the actual or experimental application of the countermeasure.

\subsection{Classification criteria}

The results of the simulations allowed the establishment of a set of criteria to be used in support of decision processes, regarding radiological protection aspects.

The first criteria relates to the efficiency in reducing the first year dose. The standard time of application for comparison with the criteria is one week after the deposition event. The first year is the period where the highest doses are observed.

The second criteria relates to the efficiency in reducing long-term doses (50 years integrated dose for adults and 70 years integrated doses for children). Again, the standard time of application for comparison with the criteria is one week after the deposition event.

The third and forth criteria considers the effect of delay on the application of the measure in the reduction of the efficiency in reducing the first year and the reduction on the efficiency in reducing the 50- or 70-years integrated dose, for adults and children, respectively.

While applying the criteria to urban areas, to each individual radionuclide, is quite straightforward, the same is not true for rural areas. In urban areas, the percent reduction on doses for several countermeasures have not shown large variation among the different scenarios simulated. For rural areas, however, it could be observed that local conditions at the time of the accident are very relevant 
to drive the relevance of each specific countermeasure as seasonal aspects have a strong influence on doses to be received by the public, as can be seen in Figure 1. Also, specific habits, particularly the degree of self-sustaining feeding habits of population groups will have relevant influence on their doses and on the need of substitute food supply, as can be seen in Figure 2, where it can be seen the difference on the relevance to dose of different food items according to the season when the accident occurs.

\subsection{Future developments}

Next steps shall include the raising of data to complement non-radiological aspects, such as population habits and the availability of materials and equipments at the target area, Also criteria related to the generation of wastes according to their type, amount and radionuclide content shall be developed. Radioecological studies shall also continue to improve knowledge on the behavior of radionuclides in tropical environments, with a focus on those radionuclides that may be relevant to doses to the public in the event of a nuclear accident.

\section{CONCLUSIONS}

After the Goiania accident, a long term project aiming on developing tools for environmental assessments after an accidental contamination has been developed at IRD/CNEN. Activities developed included the development of software, experimental works to create a database on environmental transfer parameters and information adequate to tropical climate countries, computer simulations of environmental scenarios to derive parameter values and effectiveness of protective measures for typical tropical scenarios. Currently, a database on protective measures is being created aiming to feed a multicriteria decision making model, also under development. In this stage radiological criteria are being defined and future works shall deal with non-radiological criteria such as those needed to describe the need on infrastructure and the wastes generated from the remediation measures.

\section{Acknowledgments}

To CNPq for the grants provided to fulfill this work.

\section{References}

[1] The radiological accident in Goiânia. International Atomic Energy Agency (1988).

[2] Environmental consequences of the Chernobyl accident and their remediation: twenty years of experience. Report of the Chernobyl Forum Expert Group 'Environment'. Radiological Assessment Reports Series, International Atomic Energy Agency (2006).

[3] The Radiological Accident in the Reprocessing Plant at Tomsk. Accident Response Series. International Atomic Energy Agency (1998).

[4] Schenker-Wicki A. The Use of Multi-criteria Analysis (MCA) for Evaluating Feasible Countermeasures after an Accidental Release of Radioactivity. IVth International Symposium of Radioecology, Cadarache. IUR, (1988).

[5] Zeevaert, T., Bousher, A., Brendler, V. et al.: Evaluation and ranking of restoration strategies for radioactively contaminated sites. J. Environ. Radioact. (2001) 33-50

[6] Rochedo E.R.R., Conti L.F.C.; Paretzke H.G. PARATI- a dynamic model for radiological assessments in urban areas - Part I. Modelling of urban areas, their contamination and radiation fields. Radiat. Environ. Bioph. (1996) 243-261. 
[7] Conti L.F.C., Rochedo E.R.R., Amaral E.C.S.: Desenvolvimento de um sistema integrado para avaliação de impacto radiológico ambiental em situações de emergência. Rev. Brasil. P\&D (2002) 872-879.

[8] Rochedo E.R.R.; Conti L.F.C.; Paretzke H.G.: PARATI - A dynamic model for radiological assessments in urban areas - Part III. Parameter uncertainty analysis. Radiat. Environ. Bioph. (1998) 285-292

[9] Salinas I.C.P., Conti C.C., Rochedo E.R.R., Lopes R.T.: Gamma Shielding Factor for Typical Houses in Brasil. Radiat. Prot. Dosim. (2006) 420-424.

[10] Vinhas, D.M., Rochedo, E.R.R., Wasserman, M.A.V., Conti L.F.C.: Modeling the dynamics of radionuclide concentration in food after an accident in tropical areas. Rev. Brasil. P\&D, v.7, (2000). 139-144.

[11] Silva, D.N.G., Rochedo, E.R.R., Wasserman, M.A.V.: Remediation strategies after nuclear or radiological accidents: part 1. database development. International Nuclear Atlantic Conference INAC (2009).

[12] Vetere M.I.C.; Rochedo E.R.R.; Conti L.F.C.: Aplicação do Sistema Integrado de Avaliação de Impacto radiológico Ambiental em situações de Emergência. Rev. Brasil. P\&D, (2002) 729-736.

[13] Pesquisa de orçamentos familiares 2008-2009 - Avaliação nutricional da disponibilidade domiciliar de alimentos no Brasil. Instituto Brasileiro de Geografia e Estatística, 2010. 